and cover subjects as diverse as electron paramagnetic resonance and the flight orientation of birds.

Under the title "Characteristics of Masers" G. M. Strakhovskii and I. V. Cheremiskin report experimental work on the relative stability and reproducibility of the oscillation frequency of a maser using the 3,3 line of ${ }^{14} \mathrm{NH}_{3}$, and its dependence on various operating parameters. N. G. Basov, V. S. Zuev and K. K. Svidzinskii describe similar work on the $\mathrm{ND}_{3}$ maser, which produces a frequency near $1,600 \mathrm{Mc} / \mathrm{s}$, significantly lower than that of the $\mathrm{NH}_{3}$ maser which operates in the region of 24,000 $\mathrm{Mc} / \mathrm{s}$. Theoretical aspects of the frequency characteristics of the ammonia maser are considered by A. N. Oraevskii, who includes proposals for the use of oppositely directed beams and the reduction of beam velocity to improve the performance of the maser. The fourth paper, by $\mathrm{K}$. K. Svidzinskii, is a comprehensive theoretical treatment of a subject related to the field of molecular beam maser research: the hyperfine structure of the rotational spectra of molecules.

The ammonia maser as a reproducible frequency source has been superseded in turn by the crsium atomic beam standard and by the hydrogen maser. A.s a low-noise amplifier the solid-state maser is more practicable and versatile. In spite of the dwindling interest in the ammonia maser itself there is a good deal of instructive material in these translations, and the bibliography may reveal papers the existence of which could not previously be easily discovered.

J. H. SANDERS

\section{ELECTRON AND VACUUM PHYSICS IN EASTERN EUROPE}

Proceedings of the Symposium on Electron and Vacuum Physics, Hungary, 1962

Chief Editor: Ernö Winter. Pp. 506. (Budapest: Akadémiai Kiadó, Publishing House of the Hungarian A.cademy of Sciences, 1963.) 11 dollars.

IN the present-day unhappy division of Europe into the Western and Eastern spheres of influence, it is always of interest to gain knowledge of scientific activity in Eastern Europe. In this respect, this excellently printed volume is valuable in presenting fifty-five papers read at the Budapest Conference in 1962, which was devoted to electron and ion physies and optics, vacuum. physics and techniques and gaseous discharges. All except six of the papers are from Hungary, Roumania, Poland, Czechoslovakia and East Germany, with the majority from the first of these countries, but with virtually no influence (except in references) from the U.S.S.R. Admittedly six of the papers are in the Russian language, but they are chiefly by Czechs, the remaining forty-nine are in English or German with the exception of that, in French, by M. Degras (from Saclay) on the investigation of sorption by electron bombardment. Moreover, the many references collected in the Eastern European papers are primarily concerned with American, British and German work. Indeed, two factors are noteworthy: the apparently small influence from the U.S.S.R. in this field of activity and the indications that the Eastern European countries suffer a paucity of modern scientific equipment.

The direct British contribution is small and represented by papers from L. Holland, on surface contamination in vacuum evaporation systems, and by D. Gabor, on gas discharge work arising out of his experiments on thermionic generators. The well-known names of $D$. Alpert from the United States and P. Redhead from Canada appear, but otherwise the influence is dominantly Hungarian.

As the content of the papers of the few authors from the West is more readily available in recent American. and British journals, the chief interest here is to survey briefly the topies covered within the papers from Eastern Europe. Electron and ion dynamies and optics are well represented, including two theoretical papers on quadrupole mass filters, one in Russian by C. J. Javor and a second in German by G. Otto. Among the papers on mass spectrometers is one by K. András, A. Dallos and J. Erdélyi in German, giving preliminary details of a new type of mass spectrometer, in which the ions move in spiral trajectories and selection is made at a specific angle of rotation in the track. Field emission cathodes and microscopes are clearly popular research topics, as is also secondary electron emission, particularly from the theoretical point of view. Other topics include oxidecoated, cermet and hollow cathodes, cæsium alloy photocathodes, conduction in gases including cæsium plasma, breakdown initiation and Penning discharges. As in Western Europe, investigations of gas sorption on filaments appear and the omegatron is a popular research tool for gas analysis observations, but one wonders whether the many papers published on the vagaries of this instrument might not eventually condemn it as a commercial device compared with the miniature mass spectrometer of the deflexion type. The hot-cathode ionization gauge in relation to ultra-high vacuum measurement is the subject of four papers, including one giving details by C. Brieman and R. Leyniers in English on a transistorized power supply for emission regulation. One paper on a $2-\mathrm{kW}$ experimental electron-beam welder appears in English by E. Fóti and one on vacuum-tight windows for infra-red radiation detectors.

This volume is chiefly of use to the scientist engaged with research on electron tubes; it contains little of vital interest to the vacuum physicist able to consult the much vaster Western scientific literature. Perhaps one should be cautious here, however, after reading in German the opening paper by $\mathbf{E}$. Wintor which surveys the Hungarian research results in the fields of electron and vacuum physics within the period 1926-50, because he claims that several techniques in electron physies have originated in Hungary. Though this volume is unlikely to have much influence in Britain and America, it is nevertheless warmly welcomed as a record of research in countries with a growing scientific tradition. The excellence of the English used in many of the papers by Hungarian authors is, moreover, a tribute to their linguistic powers and to the first-class editorial work in preparing this book.

J. YARWOOD

\section{'OLD NICK'S' METAL}

Nickel : an Historical Review

By F. B. Howard-White. Pp. xiii +350 . (London: Methuen and Co., Ltd., 1963.) $45 s$.

THIS is no ordinary historical review, in the sense of scholarly detachment, but a man writing on the subject of his working life. There is perhaps a shadow of 'Pygmalion' in such devotion to one grey metal of less universal application than iron and of much inferior appearance to chromium. Nevertheless, nickel as an alloying element has played perhaps tho most dominant part in the improvement of steels (based on iron), provided the ideal undercoating to chromium plate, and furnished the cutler with an amazingly good but cheaper substitute for silver. The author of this book concludes, in fact, with the attainment of manned space flight in a capsule sheathed in nickel-bearing materials.

The earliest known uses of nickel are the fortuitous occurrences in copper and bronze articles found in Antioch, Ur, and Kish, dating back some 3,500 years. The sourco of the material may be coincident with that of similar objects found in China. Undoubtedly, a favourite source of nickel was that of meteoric iron, and the word for 